Research Article

\title{
Research on Shape Changes in Cylinder Electrodes Incident to Micro-EDM
}

\author{
Xiaopeng Li $\mathbb{D}^{1,},{ }^{1,2}$ Yuangang Wang $\mathbb{D}^{2},{ }^{2}$ Yu Liu $\left(\mathbb{D},{ }^{3}\right.$ and Fuling Zhao ${ }^{1}$ \\ ${ }^{1}$ School of Mechanical Engineering, Dalian University of Technology, Dalian 116024, China \\ ${ }^{2}$ School of Mechanical Engineering, Dalian University, Dalian 116622, China \\ ${ }^{3}$ School of Mechanical Engineering, Dalian Jiaotong University, Dalian 116028, China \\ Correspondence should be addressed to Yuangang Wang; wygang2000@163.com
}

Received 22 December 2018; Revised 13 March 2019; Accepted 1 April 2019; Published 2 May 2019

Academic Editor: Yuanshi Li

Copyright (c) 2019 Xiaopeng Li et al. This is an open access article distributed under the Creative Commons Attribution License, which permits unrestricted use, distribution, and reproduction in any medium, provided the original work is properly cited.

\begin{abstract}
This paper discusses electrode wear changes under different operating conditions. A series of experiments were designed and conducted using an EDM machine tool with a rectangular pulse power supply. The phenomena of the cylinder electrode shape changes were abstracted from the experiments; the change mechanisms of the end face are discussed and verified by experimental data and interrelated theory. The results disclose that the shape of an electrode is subject to pulse-on time, discharge current density, and electrode polarity.
\end{abstract}

\section{Introduction}

Electrical discharge machining $(\mathrm{EDM})$ is a well-established process that is used to machine high precision dies, molds, and parts with complex features and high aspect ratios. Various micro-EDM types are used for the machining of micro or miniature dies and molds.

It is well known that the electrode wear in EDM affects the accuracy of the machined form [1], and this is one of the two main challenges of micro die-sinking EDM [2]. The uniform electrode wear compensation method [3] and realtime electrode wear compensation method [4] are used for micro-EDM milling. The electrode wear estimation model [5] is used for EDM drilling, and the problems created by electrode wear become more complicated and such wear compensation methods are not possible in commercial EDM. Many studies have been carried out to decline the electrode wear ratio. Various types of EDM electrodes such as electrically conductive CVD diamond $[6,7]$, PCD coating [8], boron-doped CVD diamond [8], and $\mathrm{Cu}-\mathrm{ZrB}_{2}$ coating [9] are used to achieve low wear. Some scholars put forward enhancement of the wear speed of an electrode to ensure that the electrode contours maintain integrality [10], which obtains a certain effect. Side-insulation of an electrode with epoxy resin [11] and an electrode encased in a dielectric jacket [12] have been developed. $\mathrm{A} \mathrm{Cu}-\mathrm{ZrB}_{2}$ coating is used on the outer peripheral surface of copper electrodes to reduce wear and retain the electrode shape during the EDM process [13].

People are not satisfied with the results described above and have begun to study electrode shape changes based on different EDM parameters, which is a basic method to improving the practicality of this process. End-tip concavity under specific machining conditions is first encountered [14]. Such concavities are also measured [15], and similar tip formations have been observed with low pulse energy [16]. These are regarded as changes of the discharge intensity [14] and debris [17]. High-frequency electrical currents have an important effect on the electrode shape [13], which was first analyzed as a the skin effect [18]. The relationship between the electrode shape and the pulse frequency is discussed, and different electrode tip ends are obtained [19]. However, all the studies mentioned above involved the electrode shape and its reasons. The relationship between the electrode shape and the EDM parameters has not been reported to date. 
Hence, this paper reports on the investigation of the reciprocal relationships between cylinder electrode shape changes and the EDM parameters. The first part of this paper contains the experimental data obtained from a series of experiments with different parameters. Next, the dynamical changes of the electrode shape are abstracted and studied by the skin effect, the tip effect, and the breakdown theories. Lastly, the mechanisms of electrode shape changes are concluded through a discussion of the experimental data.

\section{Experimental Setup}

Experiments are conducted with a Sodick AD30 Ls linear motor equipped EDM machine to investigate cylinder electrode shape changes. The machine is equipped with the SVC circuit that can provide a rectangular pulse with the maximum frequency of $1 \mathrm{MHz}$.

Cylinder electrodes having a $1 \mathrm{~mm}$ diameter are used to drill holes in a SUS420 stainless steel workpiece. The polarity, pulse duration, pulse interval, material, and current peak are selected for investigation, as shown in Table 1. Other discharge conditions are maintaining a discharge voltage of $16 \mathrm{~V}$, a servo voltage of $10 \mathrm{~V}$, the EDM oil working fluid, and an electrode jump frequency of 30 times per minute. Side flushing is applied. The experiments are performed at ambient temperature. The tool electrodes are prepared on-site by the wire electrode discharge grinding method.

The cross sections of the holes were cut along their axis by a wire EDM machine (AD360 Ls). After machining, the holes and the electrodes were analyzed by means of a metallographic microscope, SEM and EDS.

\section{Experimental Results and Discussion}

3.1. Change Process of Electrode Shape. The dynamical changes of the electrode shape are studied. Since spark erosion occurs on a workpiece in the working fluid and the shape of an electrode is transferred onto the workpiece, the changes of the electrode shape over time are tracked by recording the cross sections of the different holes under the no. 1 condition of Table 1 . Images of cross section are made and observed every 2 minutes (Figure 1). There is some enlightenment of the final shape of the electrode, although these images are not continuous.

The shape changes can be clearly seen in Figure 1. It is evident that the convex shape comes into being in the 5 th minute. Extending the processing time, the convex height appears slowly and grows to some degree while remaining steady from the 9th minute to the 15th minute. Meanwhile, three electrode shapes and corresponding cross sections of the machined hole with three different machining times are presented in Figure 2. It can be seen in Figure 2 that the shape of the electrode remains stable after 60 minutes of machining conforming well with the convex tip shape at the hole bottom shown in Figure 1.

The electrode is parameterized, as described in Figure 3, to conveniently analyze the results. $D$ is the diameter of the electrode, $r$ and $s r$ are the corner radius and the spherical radius of the concave tip, respectively, $\delta$ represents the thickness of the skin layer, and $h$ is ring width of the end face.

\subsection{Mechanism Analysis of the Electrode Shape Change.} The electrode is usually connected to the negative terminal of the power supply in micro-EDM. As the electric field is established between the electrode and the workpiece, the free electrons on the electrode are subjected to electrostatic forces. If the work function or the bonding energy of the electrons is less than the electrostatic forces, electrons would be emitted from the electrode in a state of cold emission [20]. These "cold emitted" electrons are then accelerated toward the workpiece through the oil and then collide with the electrons and dielectric molecules. Such a collision may result in the ionization of a dielectric molecule. Thus, more positive ions and electrons would be generated. This cyclic process would increase the concentration of electrons and ions in the dielectric medium. This concentration would be so high that the matter existing in that channel could be characterized as "plasma" [21], and thus, all of a sudden, an avalanche motion of electrons occurs [22]. The plasma generates a very large current as well as internal electric and magnetic fields [23]. As the electric and magnetic fields fluctuate extremely, the inducted electric and magnetic fields generate a discharge circuit, which includes the tool electrode. These inducted electric and magnetic fields that are applied to the tool electrode create the so-called skin effect [24]. As a result, the electric field is driven away from the conducting interior and is concentrated on the surface of the electrode [19]. Under the condition of high frequency discharge, this unique nonuniform energy distribution will affect the microprocess of EDM.

When the electrode is connected to the negative electrode of the micro-EDM power supply in the breakdown phase, the time-dependent current is distributed nonuniformly throughout the cross section of the electrode due to the existence of the skin effect (Figure 4(a)), and there is much more current on the external conductor surface than in the interior. Meanwhile, a strong electric intensity appears on the edge due to the tip effect. Therefore, the discharge probability of the edge of the end face increases significantly (Figure 4(b)), causing large wear on the surface of the tool electrode. The corner radius, $r$, appears as shown in Figure 4(c). On the other hand, the number of electrons emitted in the central section of the cylinder electrode is small because of the skin effect, and in this region, discharge owing to the negative electrode is very difficult, so the discharge probability of the center is small, so the material removed from the center of the electrode is small, and accordingly, the distance between workpiece and the electrode is also small (Figure 4(d)), which will be beneficial to building up the discharge channel near the central line. As the distance decreases, there is enough time for positive ions to reach the negative electrode, and as a result, the material at the center of the electrode is removed 
Table 1: Experimental conditions.

\begin{tabular}{|c|c|c|c|c|c|c|}
\hline No. & Polarity & Pulse-on time $(\mu \mathrm{s})$ & Pulse-off time $(\mu \mathrm{s})$ & Material & Current peak (A) & Machining time (min) \\
\hline 1 & + & 1 & 1 & $\mathrm{Cu}$ & 3.4 & 15 \\
\hline 2 & + & 1 & 1 & $\mathrm{Cu}$ & 3.4 & $15,30,60$ \\
\hline 3 &,+- & 1 & 1 & $\mathrm{Cu}$ & 3.4 & 15 \\
\hline 4 & + & 1 & $1,10,20,200$ & $\mathrm{Cu}$ & 3.4 & 15 \\
\hline 5 & + & $1,5,10$ & 1 & $\mathrm{Cu}$ & 3.4 & 15 \\
\hline 6 & + & 1 & 1 & $\mathrm{Cu}$ & $3.4,9.4,15.4,21.4,27.4,33.4$ & 15 \\
\hline 7 & + & 1 & 1 & $\mathrm{Cu}, \mathrm{W}$ & 3.4 & 15 \\
\hline
\end{tabular}

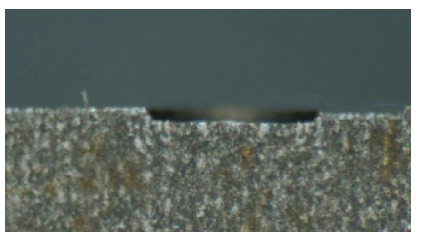

(a)

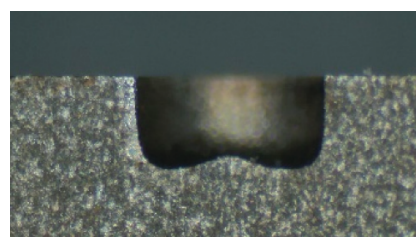

(e)

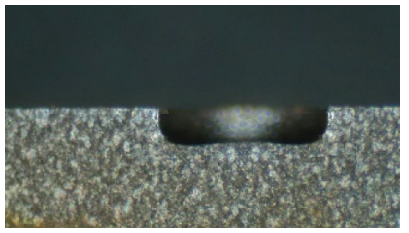

(b)

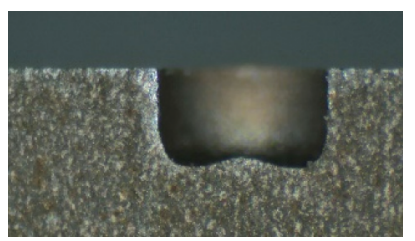

(f)

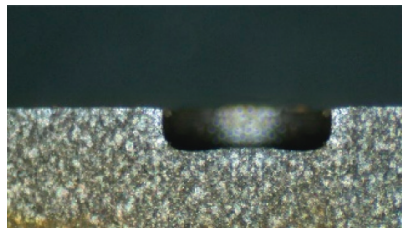

(c)

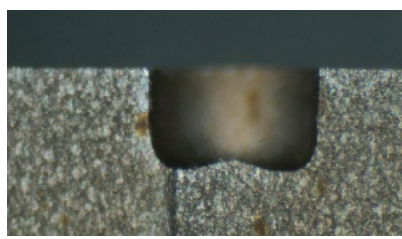

(g)

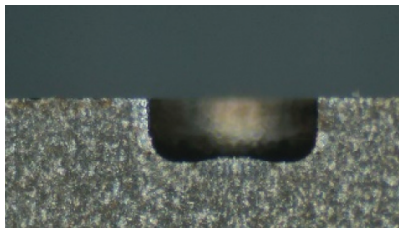

(d)

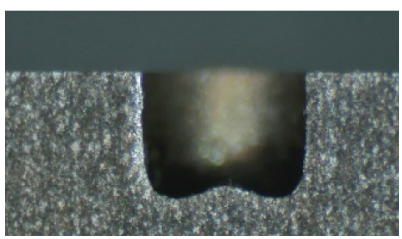

(h)

Figure 1: Shape changes of the holes over time (no. 1 of Table 1). (a) $1 \mathrm{~min}$. (b) $3 \mathrm{~min}$. (c) $5 \mathrm{~min}$. (d) $7 \mathrm{~min}$. (e) $9 \mathrm{~min}$. (f) $11 \mathrm{~min}$. (g) $13 \mathrm{~min}$. (h) $15 \mathrm{~min}$.
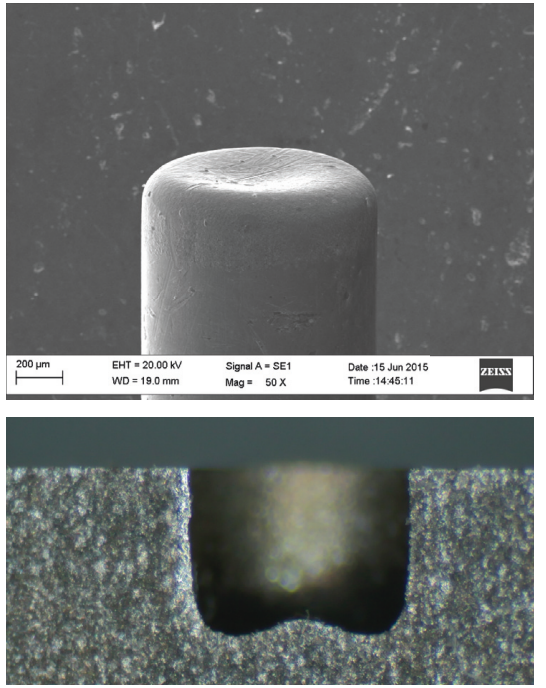

(a)
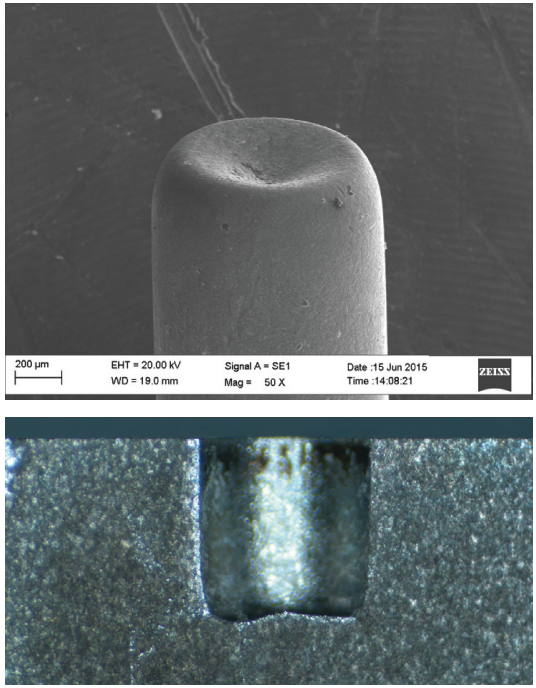

(b)
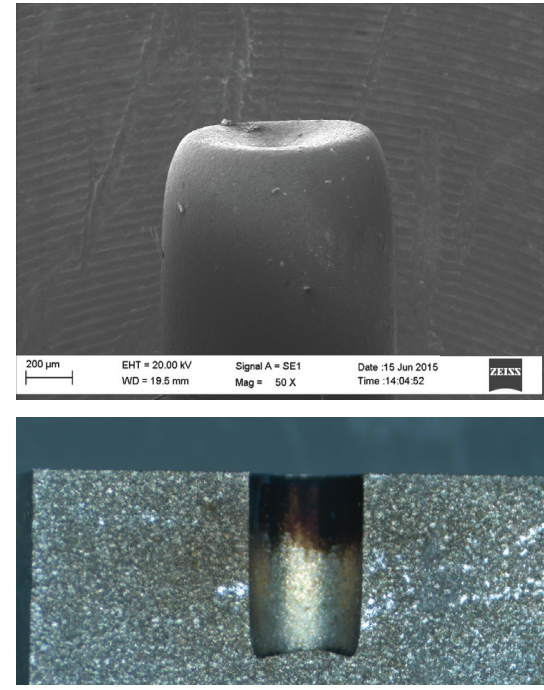

(c)

FIgURE 2: Electrode shape changes with different machining times (no. 2 of Table 1). (a) $15 \mathrm{~min}$. (b) $30 \mathrm{~min}$. (c) $60 \mathrm{~min}$.

by receiving heat flux from ions. At the end, a concave surface is formed on bottom of the electrode as shown in Figure 4(e).

After changing the polarity of the electrodes, the electrode is connected to the positive pole of the power supply. During the discharge breakdown stage, the electric field intensity distribution between the electrode and the workpiece is not uniform due to the tip effect. According to the cathode field-induced electron emission theory of metals, with the increase of the electric field intensity, the free electrons on the workpiece will tunnel through a metal surface barrier by being compressed by a strong electric field so that the electrons are first emitted on the edge of the electrode face (Figure 5(b)), which makes the wear at the edge of the electrode end obviously increase (Figure 5(c)). However, the number of electrons emitted by the workpiece 


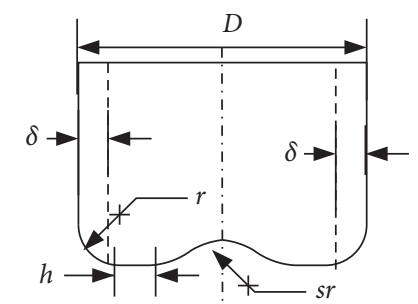

FIGURE 3: Geometry of the model electrode.

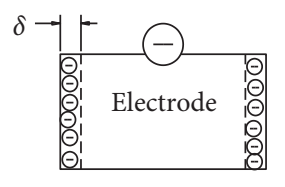

Workpiece

(a)

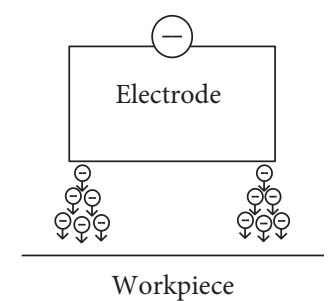

(b)

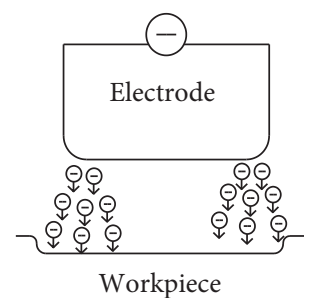

(c)

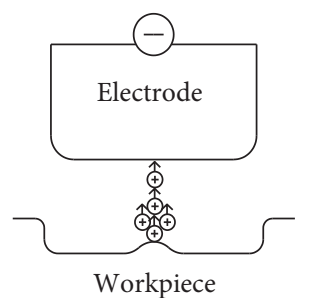

(d)

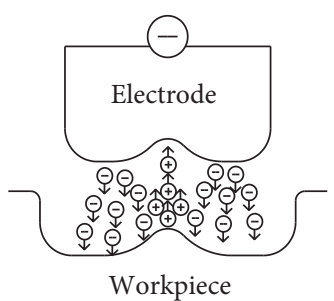

(e)

FIGURE 4: Graphic of the changing process of the electrode bottom (positive polarity machining).

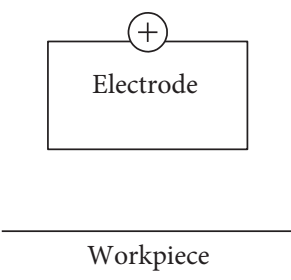

(a)

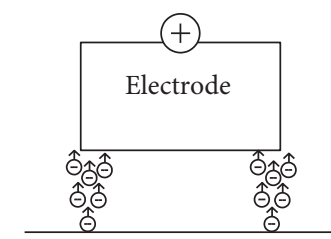

Workpiece

(b)

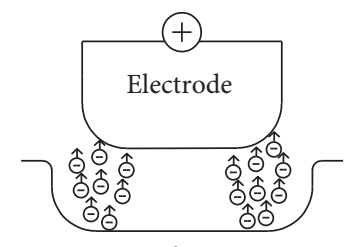

Workpiece

(c)

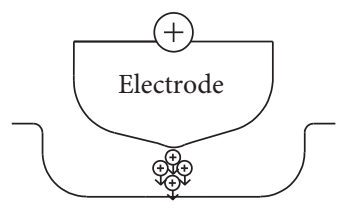

Workpiece

(d)

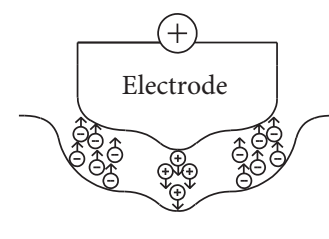

Workpiece

(e)

FIGURE 5: Graphic of the changing process of the electrode bottom (negative polarity machining).

in the central area corresponding to the electrode end surface is less, and the probability of discharge is less. Therefore, the material removal in the central area of the electrode end surface is less, and a convex surface will be formed at the bottom of the electrode (Figure 5(d)). As the distance between the workpiece and the electrode decreases, the positive ions have enough time to reach the negative electrode, so the workpiece is bombarded by ions at the bottom of the hole. Finally, a concave surface is formed at the bottom of the hole, and the convex surface formed at the end of the electrode is much sharper (Figure 5(e)). If the electrode is connected to the positive electrode in micro-EDM, the electrode will be severely worn by the large amount of electron bombardment, while the processing speed of the workpiece is relatively slow.

It is found that the gap field can be divided into three areas, namely, the action area of ions, $\mathrm{A}$, the combined action area of the ions and the electrons, $\mathrm{B}$, and the electron action area, C, as shown in Figure 6. Charges not only play their own roles by their own means but interfere with each other as well. The kinetic energy of the electrons and ions on their impacts with the surfaces of the workpiece and electrode, respectively, would be converted into thermal energy, or heat flux, on these surfaces. Such an

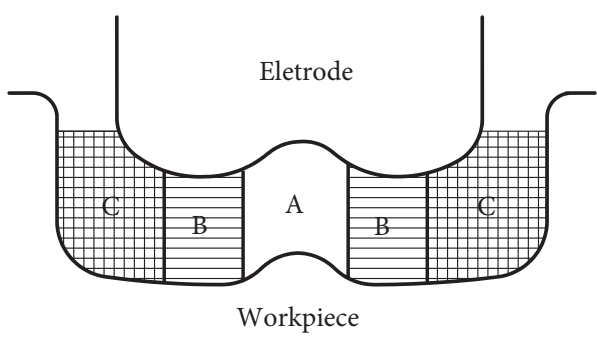

FIGURE 6: Graphic of three areas of the gap. A: the action area of ions; $\mathrm{B}$ : the combined action area of the ions and electrons; $\mathrm{C}$ : the electron action area.

intense localized heat flux leads to an extreme instantaneous rise in the temperature that would be in excess of $10,000^{\circ} \mathrm{C}$. This high temperature will melt and remove the local material in a tiny area. As the removal rate changes in different $\mathrm{A}, \mathrm{B}$, and $\mathrm{C}$ areas, the final shape of electrode is formed.

These subareas will change with the changes of the EDM parameters; therefore, the electrode acquires different geometrical shapes. The effects on the shape deformation that are caused by the EDM parameters are further analyzed by means experimental phenomena in the next section. 


\subsection{Effect of the Electrical Parameters on the Shape Change}

3.3.1. Effect of the Polarity on the Electrode Shape Change. Figure 7 shows two pictures of an electrode that was tested under the same experimental conditions, except for the electrode polarity. In Figure 7(a), where the workpiece is positively polarized (positive polarity machining), the material removal is more effective, and the electrode wear is much less. In Figure 7(b), the copper electrode is positively polarized with respect to the workpiece (negative polarity machining) and the wear of the electrode is very high, but the material removal of the workpiece is very low.

With positive electrode polarity, electrons are launched from the negative workpiece and accelerated by the potential in the gap, so they are not induced to transfer to the side surface by the skin effect before they arrive at the electrode. The removal point of the discharge channel will be a random position on the electrode bottom. The material of the bottom edge is removed more than that of the center of the end face (Figure 7(b)) because of the intensity of the electric field (the tip effect) in the beginning stage.

The experiment was continued for another 30 minutes under this condition, and the shapes of electrode and the resulting hole were obtained, as shown in Figure 8. The sharp tip appears, and this change goes beyond what is expected. The range of the skin effect extends to the entire surface of the electrode such that the electrode has a convex tip. The removal point of the discharge channel is easier to slide outside at discharge phase, and even the access point of the prebreakdown current is at any position of the electrode at breakdown phase, which means the material removal will be smaller in center place than in the other areas. This experimental phenomenon is in accordance with the analysis mentioned above.

Therefore, the electrode polarity not only greatly influences the amount of electrode material removed but also influences the position of material removal in discharging via the skin effect in these conditions.

\subsubsection{Effect of the Frequency on the Electrode Shape Change}

(1) Change of the Pulse-Off Time. For changing the pulse frequency, different pulse-off times are set while the pulse-on time is fixed at 1 microsecond (as shown in no. 4 of Table 1), and the tool electrodes after machining are observed (Figure 9). Figure 9 shows that the shapes remain similar, and they all have concave end surfaces.

It can be inferred from Figure 6 that discharging process is steady, and there is no interaction between the pulses, and the etching abilities of the $\mathrm{ABC}$ regions do not change. The skin depth affects the position of the discharge point, and its size is inversely proportional to the frequency of the discharge current. The pulse voltage applied by micro-EDM is a rectangular wave, but the current waveform of the actual discharge has a high frequency fluctuation (Figure 10). This is because the configuration balance of the discharge channel is constrained by its own magnetic field force (the magnetic pinch force), which causes a strong oscillation of the discharge channel and various vibrations produced by the high-

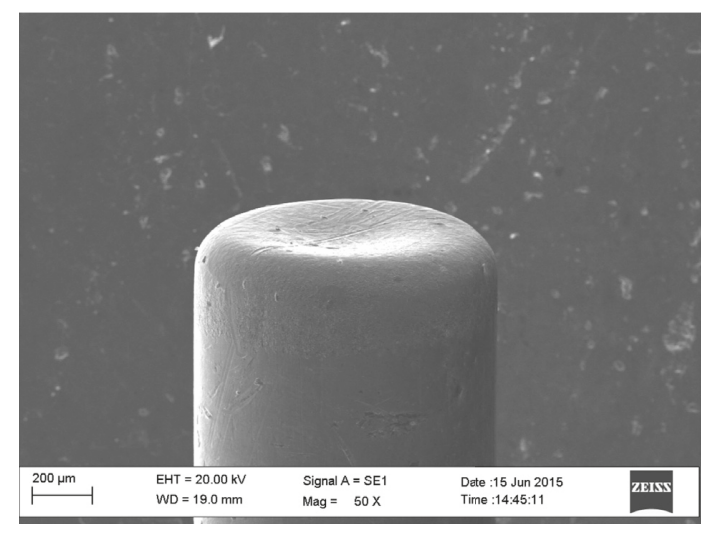

(a)

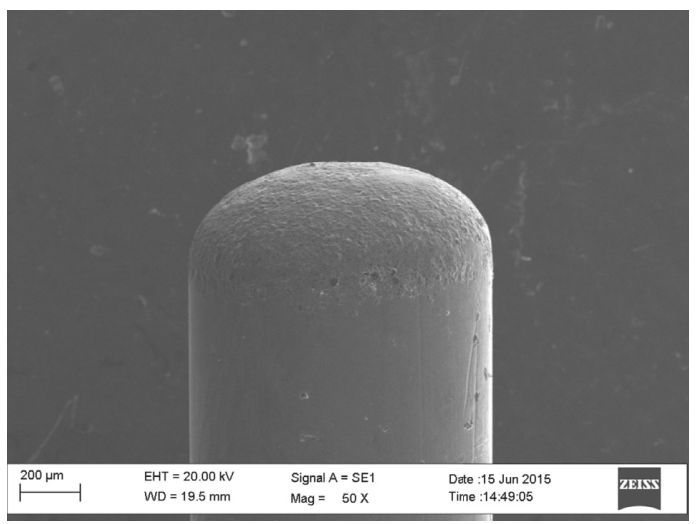

(b)

FIGURE 7: Changes of electrode shape with different polarity (no. 3 of Table 1). (a) Positive polarity machining. (b) Negative polarity machining.

speed motions of the charged particles under the action of an electric field. As a result, the current of the external circuit is superimposed with a high frequency component, and the range of the fundamental frequency is approximately dozens of times that of the set frequency. The current disturbance of the external circuit, in turn, will inevitably cause a current fluctuation in the channel, resulting in a skin effect on the tool electrode. Therefore, the actual skin depth is determined by the fluctuation frequency of the discharge current. From the breakdown theory, the evolution of the discharging current with a constant pulse-on time under the approximate conditions should be similar. Therefore, when the pulse-on time is constant, the skin depth is unchanged, the position of discharge point is not changed, and the electrode shape is also not changed.

(2) Change of the Pulse-On Time. The pulse-on time changes are $1 \mu \mathrm{s}, 5 \mu \mathrm{s}$, and $10 \mu \mathrm{s}$ in our experiments, as shown in Figure 11, where the current is held constant and the pulse-off time is $5 \mu \mathrm{s}$. It is concluded, based on Figure 11, that the depth of the concave region decreases with increasing pulse-on time.

The oscillation frequency of the discharge channel depends on the electron density. When the discharge duration is very short and the plasma channel cannot be fully expanded, the energy density of the plasma is very high, the oscillation 


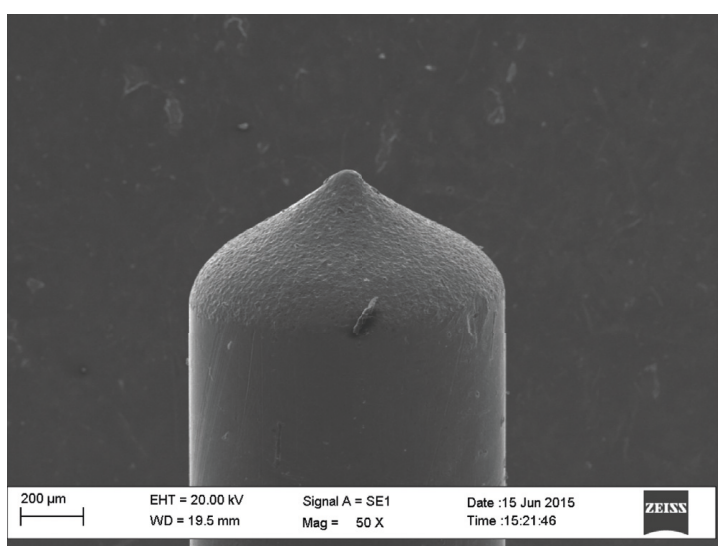

(a)

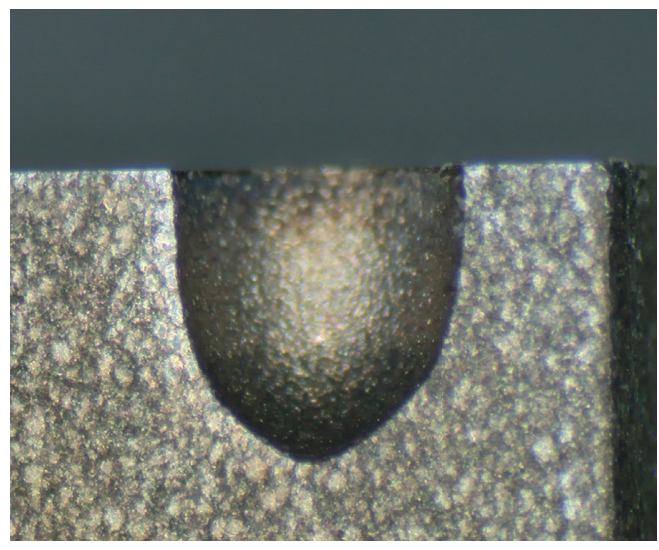

(b)

FIGURE 8: Electrode shape with positive polarity in the 45th minute (no. 3 of Table 1). (a) Electrode with a sharp tip. (b) Cross section of the hole.

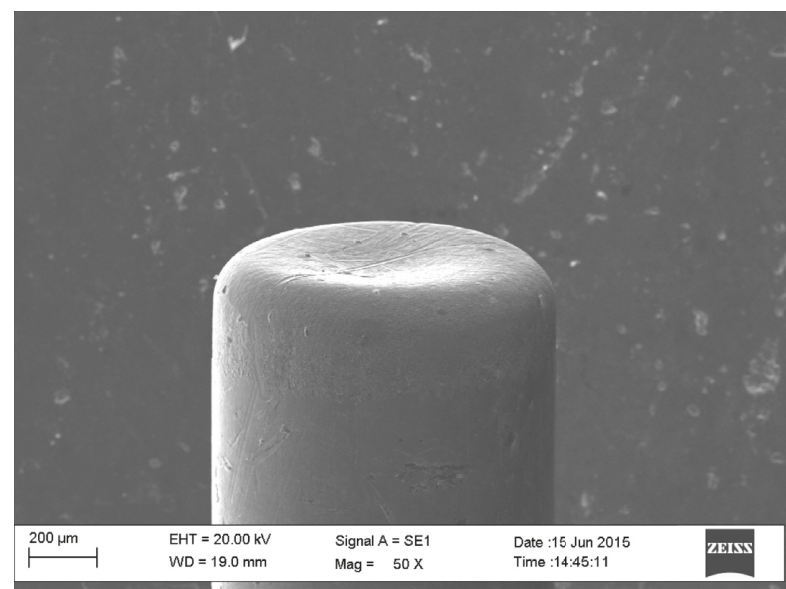

(a)

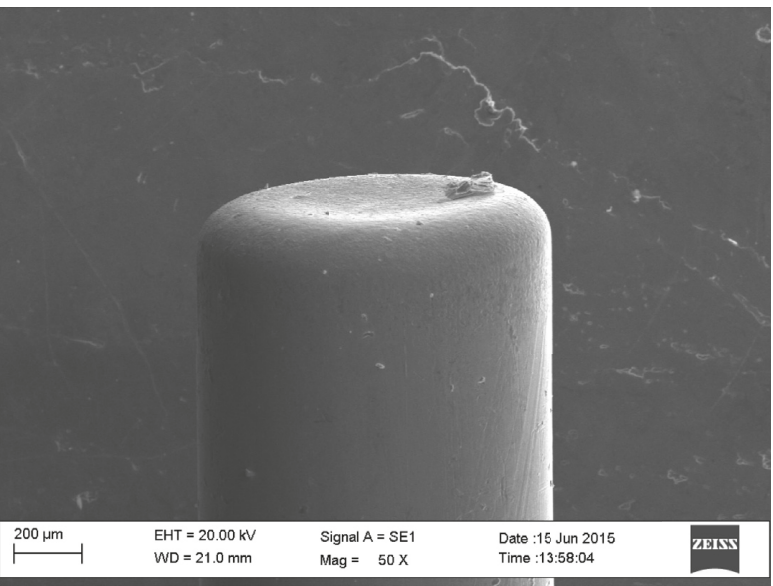

(c)

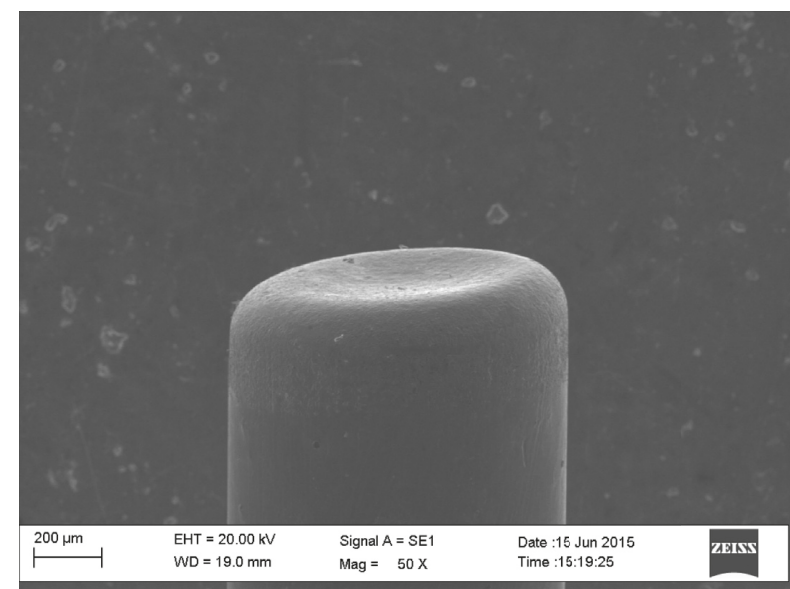

(b)

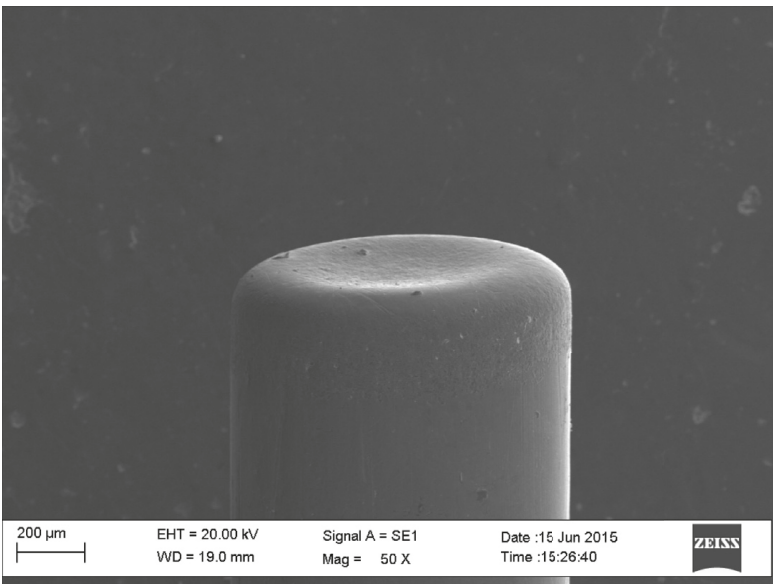

(d)

Figure 9: Electrode shape change with increasing pulse-off time (no. 4 of Table 1). (a) $1 \mu \mathrm{s}$. (b) $10 \mu \mathrm{s}$. (c) $20 \mu \mathrm{s}$. (d) $200 \mu \mathrm{s}$.

frequency is high, the skin depth is small, the initial discharge point is concentrated at the edge of the electrode, and the boundaries the $\mathrm{ABC}$ regions are obvious. With increasing pulse-on time, the energy density in the channel decreases with the expansion of the plasma, the oscillation frequency decreases, the skin depth increases, and the initial discharge point moves to the center of the electrode. Due to the long action time of the electric field on the charged particles, the 


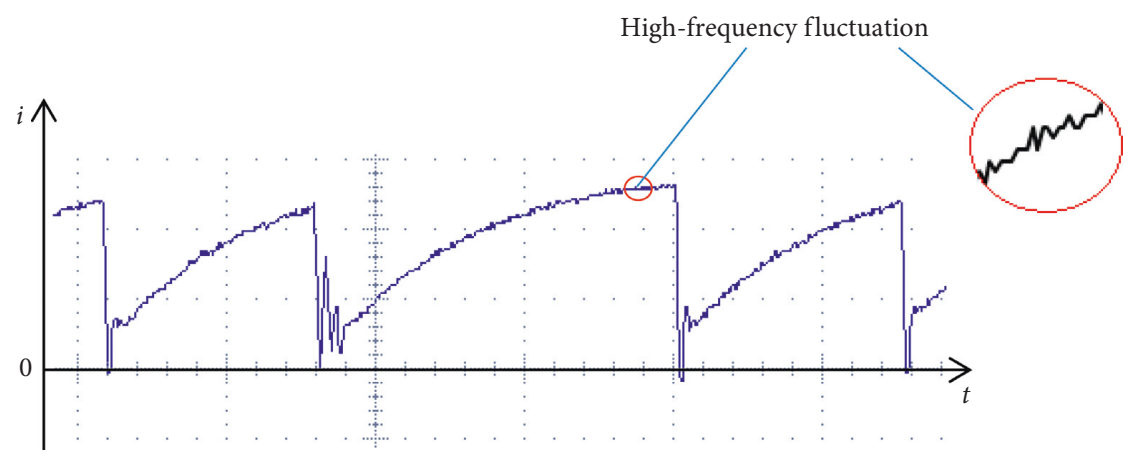

FIGURE 10: Waveform of the interelectrode discharge current.

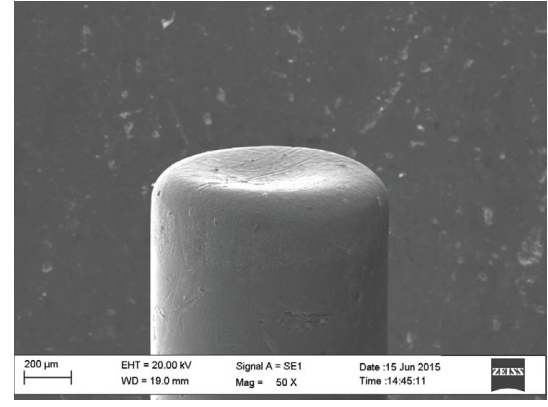

(a)

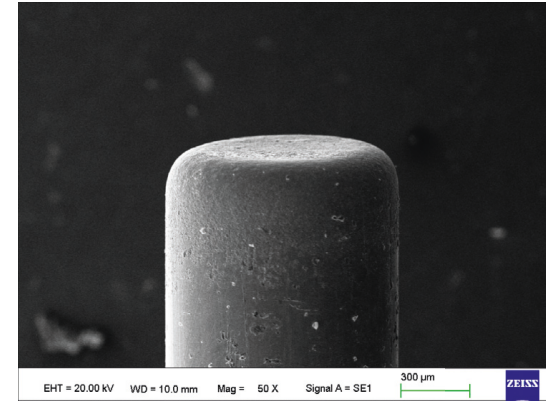

(b)

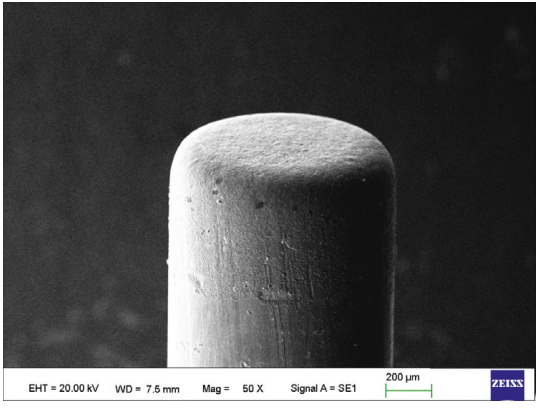

(c)

FIGURE 11: Electrode shape change with the increasing duration of the pulse-on time (no. 5 of Table 1). (a) $1 \mu \mathrm{s}$. (b) $5 \mu \mathrm{s}$. (c) $10 \mu \mathrm{s}$.

positive ions in the plasma will be fully accelerated, which will lead to a sharp increase in their kinetic energy when the ions collide with the tool surface, and more substances on the electrode surface can be removed in a large range. With the increase of the number of ions in regions $\mathrm{B}$ and $\mathrm{C}$, the wear of the electrodes in regions $B$ and $C$ increases, the boundary between $\mathrm{A}$ and $\mathrm{B}$ disappears, the radius of the circle, $r$, increases, and the width of ring, $h$, decreases.

\section{(3) Maintaining the Same Frequency with Different Pulse-Off} Times and Different Pulse-On Times. When the set frequency remains the same but the pulse-off time and pulse-on time are different, the other conditions are not changed. As seen in Figure 12, there is an obvious change in the concave state. The depth of the electrode pit with the increase of the pulse-on time decreases, and the electrode loss rate increases so that it is fully proved that the skin effect is independent of the set frequency. According to the discharge breakdown theory, by changing the pulse-on time of the discharge pulse, the degree of the skin effect action will be controlled, and then the machining morphology of the tool electrode will be properly adjusted. At the same time, under the condition of ensuring normal discharge, the pulse-off time can be reduced as much as possible to obtain maximum processing efficiency.

\subsubsection{Effect of the Discharging Current on the Electrode Shape} Change. Figure 13 describes electrode shape change with the peak current increasing from 3.4 to $33.4 \mathrm{~A}$. As shown in Figure 13, the concave radius of the end face decreases with the increase of the discharge current, and the concave shape begins to disappear at the peak current of $27.4 \mathrm{~A}$. After that, the electrode keeps its shape until the current increases to $33.4 \mathrm{~A}$.

As mentioned above, there is concavity on the bottom of the electrode due to skin effect with a low current. The charge emission during the discharge phase becomes much more intense when increasing the discharge current. The electromagnetic effects induced by the discharge current play a heavier role in the skin effect, and so the electrode shapes change drastically. The actual skin depth decreases, the $\mathrm{C}$ area is compressed, and the B area is enlarged; the energy density of the discharge channel in the $\mathrm{C}$ area is large, the tip effect is enhanced, and the angular loss and side loss are obvious. With the increase of the electron density, the effectiveness of the ions will be greatly reduced, $s r$ decreases, the pit depth becomes shallow, and end face ring width, $h$, moves toward the center. When current reaches a certain degree, the collision frequency will increase with the density, and the electrical conductivity of the skin layer will decrease due to the collisions. Then, the electrons will break the restriction of electromagnetic effect and extend inwards from the near surface. Accordingly, the thickness of the skin layer increases, the $\mathrm{C}$ area expands, the $\mathrm{A}$ area disappears, and the electrode shape changes greatly.

\subsection{Effect of the Nonelectrical Parameters on the Shape Change}

3.4.1. Effect of the Material of Electrode on the Electrode Shape Change. Shapes obtained with copper and tungsten 


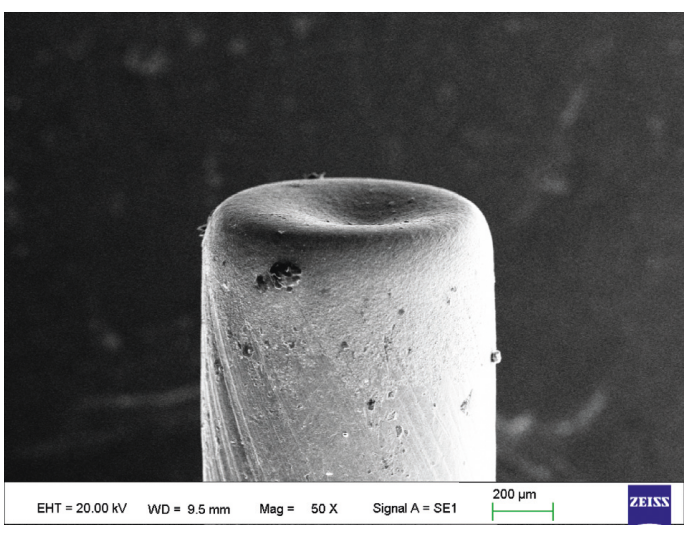

(a)

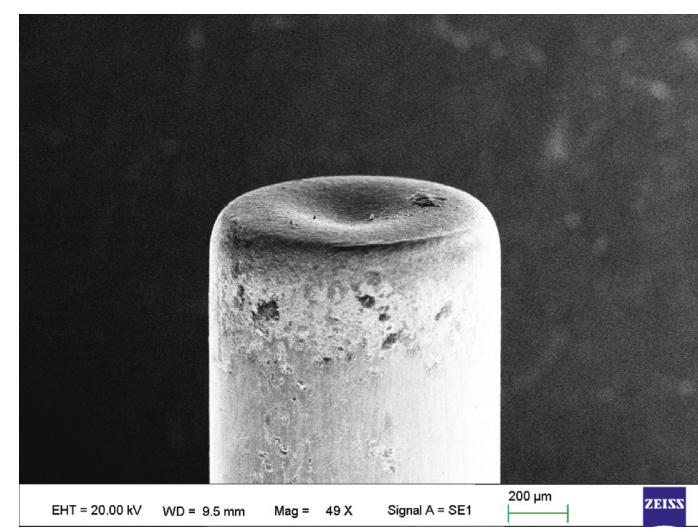

(b)

Figure 12: Changes in the electrode shape at the same pulse frequency (no. 5 in Table 1). (a) ON $1 \mu \mathrm{s}$, OFF $2 \mu \mathrm{s}$. (b) ON $2 \mu \mathrm{s}$, OFF $1 \mu \mathrm{s}$.

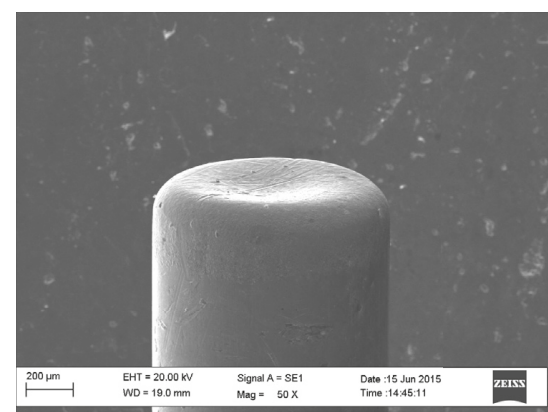

(a)

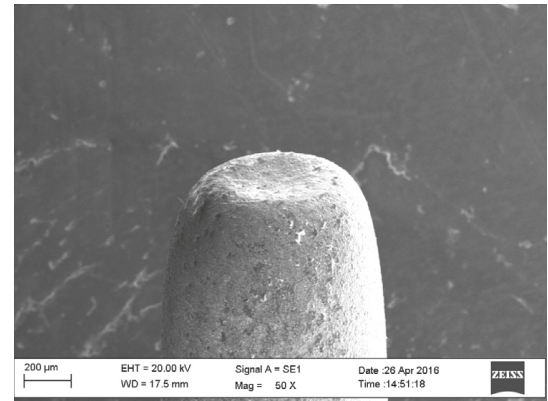

(d)

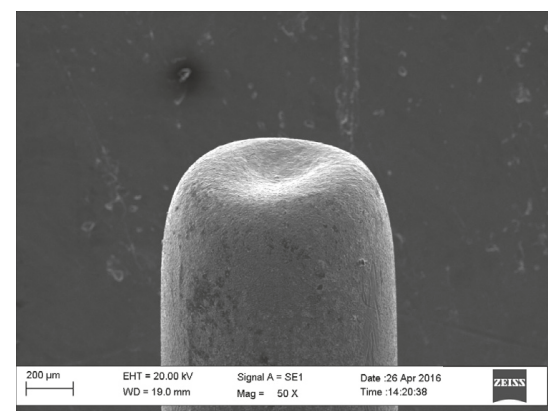

(b)

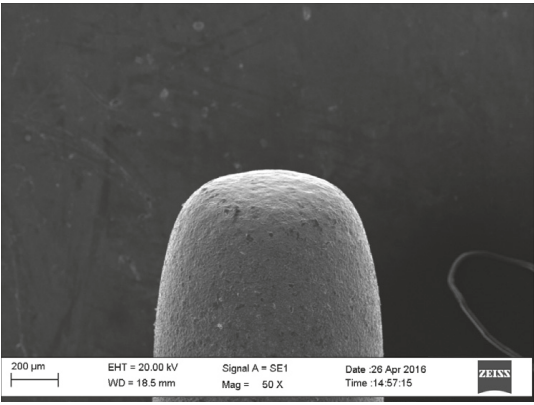

(e)

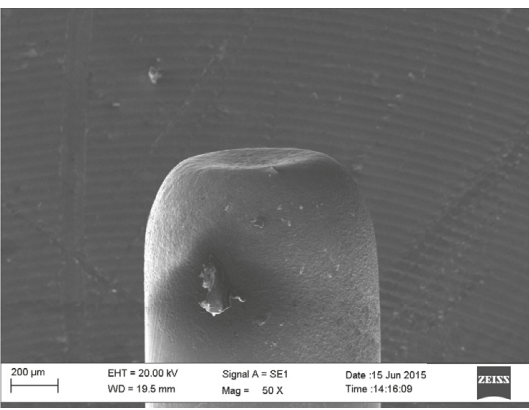

(c)

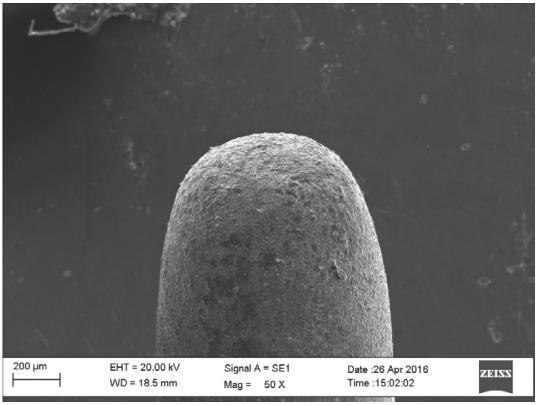

(f)

FigURE 13: Electrode shape change with increasing peak current (no. 6 of Table 1). (a) 3.4 A. (b) 9.4 A. (c) 15.4 A. (d) 21.4 A. (e) 27.4 A. (f) 33.4 A.

electrodes are shown in Figure 14. These electrodes have been selected for evaluation under the condition of no. 7 of Table 1. The results indicate that the shapes after machining are almost same.

The energy balance at the negative polarity is strongly related to the electrode material properties [25]. Tungsten has high melting and boiling temperatures $\left(3422^{\circ} \mathrm{C}\right.$ and $5555^{\circ} \mathrm{C}$, respectively), which are much higher than those of copper $\left(1084.62^{\circ} \mathrm{C}\right.$ and $2562^{\circ} \mathrm{C}$, respectively). Consequently, the wear of a copper electrode is high during the EDM process. The end face has a similar change law, but the change degree is different because of the different material properties.
3.4.2. Debris Distribution. The flushing method and electrode jump were proposed and used to analyze the effect of debris on electrode shape, which would improve the ejection of debris from the gap [26]. Figure 15 shows the final shape of the electrode after 15 minutes of processing by changing the jump time of the electrode, and there is no obvious difference between Figures 15 and 7(a). Figure 16 shows the final shape of the electrode after 15 minutes of machining by changing the spindle rotation speed. A concave shape still exists at the end of electrode. In these experiments, the depth of the hole machined by EDM is less than $3 \mathrm{~mm}$, and the effect of the debris is limited to a change in the length of the gap created by the formation of a "conductive bridge" and 


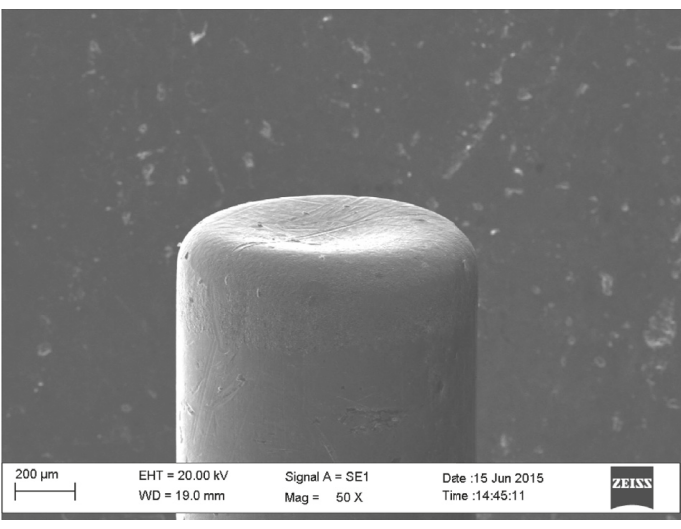

(a)

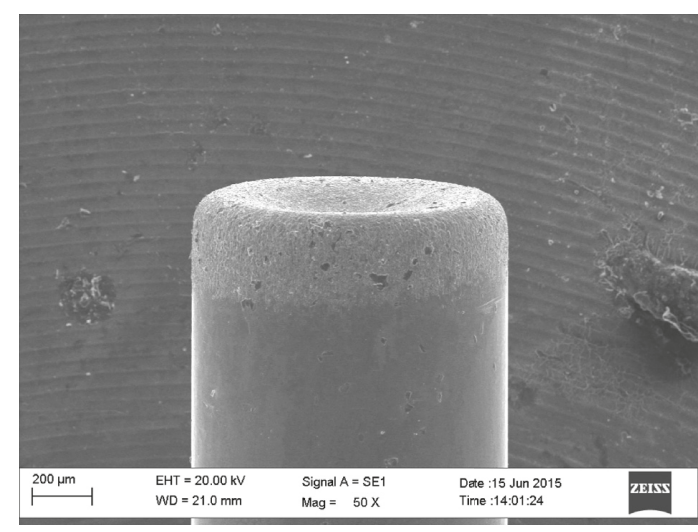

(b)

Figure 14: Electrode shape change with different electrode materials (no. 7 of Table 1). (a) Copper electrode. (b) Tungsten electrode.

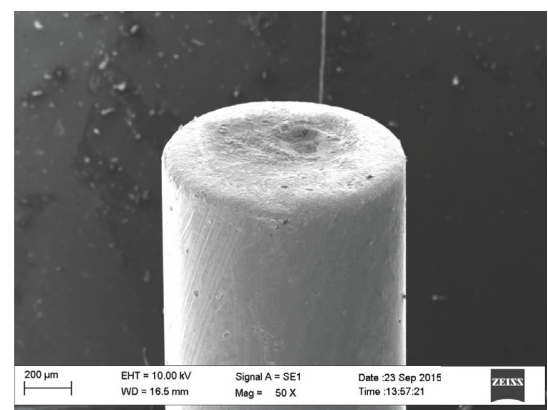

(a)

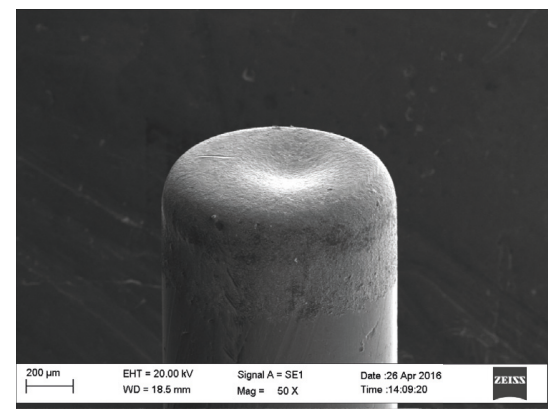

(b)

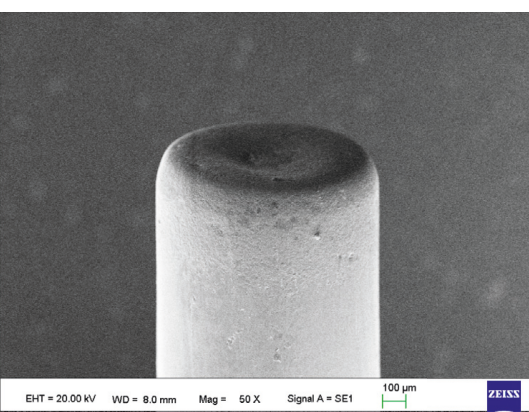

(c)

Figure 15: Shape change with electrode jump (no. 1 of Table 1). (a) up000: $0 \mathrm{~s}$. (b) up020: 0.2 s. (c) up100: $1.0 \mathrm{~s}$.

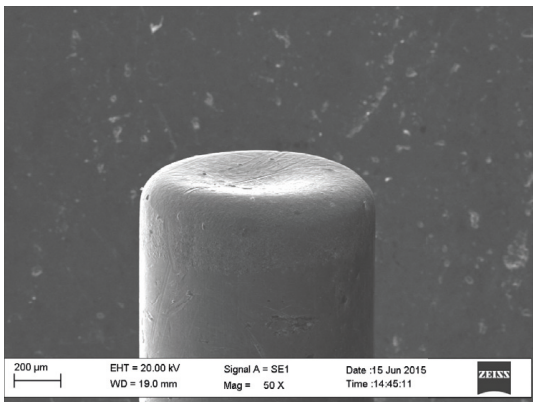

(a)

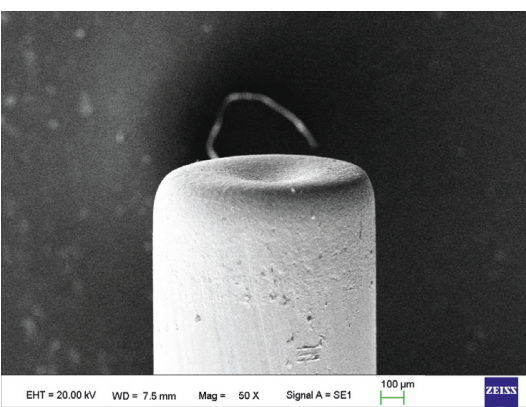

(b)

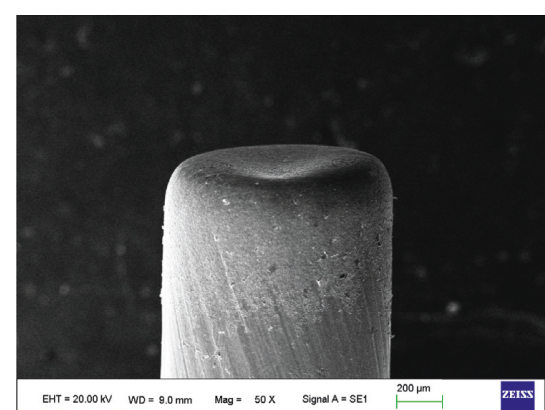

(c)

Figure 16: Shape change with flushing (no. 1 of Table 1). (a) s: $0 \mathrm{r} / \mathrm{min}$. (b) s: $10 \mathrm{r} / \mathrm{min}$. (c) s: $20 \mathrm{r} / \mathrm{min}$.

being kept in a stable status. Therefore, the concave shape of end face is not attributed to debris being ejected from the discharging gap.

\subsubsection{Deposition of the Electrode Material. EDS is adopted} to analyze the bottom material of the hole (Figure 17). Figure 17 (a) shows a section profile of the hole, and Figure $17(\mathrm{~b})$ is result of the energy spectrum analysis. It can be seen in Figure 17 that copper is detected at the center of the bottom and the percentage of copper is approximately
$1.73 \%$. It is well known that the copper will be ejected to the surface of workpiece through discharging [27]. This is not yet enough information to declare, from the low percentage of copper, that deposition is the dominant factor behind this phenomenon.

\section{Conclusions}

A series of experiments were designed and conducted using an EDM machine with a rectangular pulse power supply. The mechanisms of the rod electrode shape deformation are 


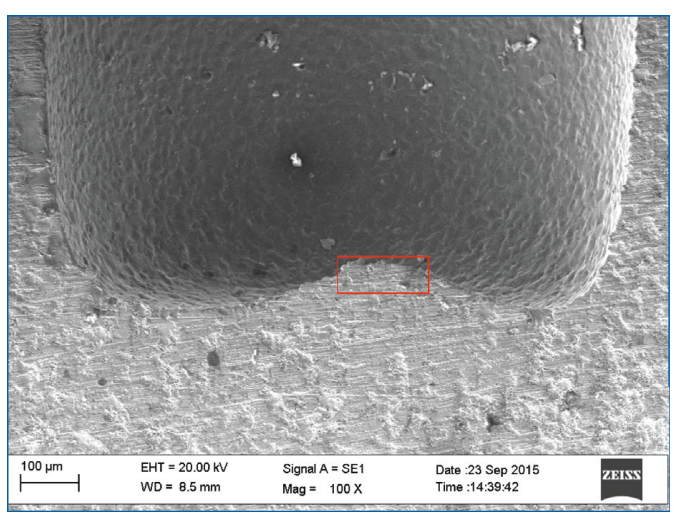

(a)

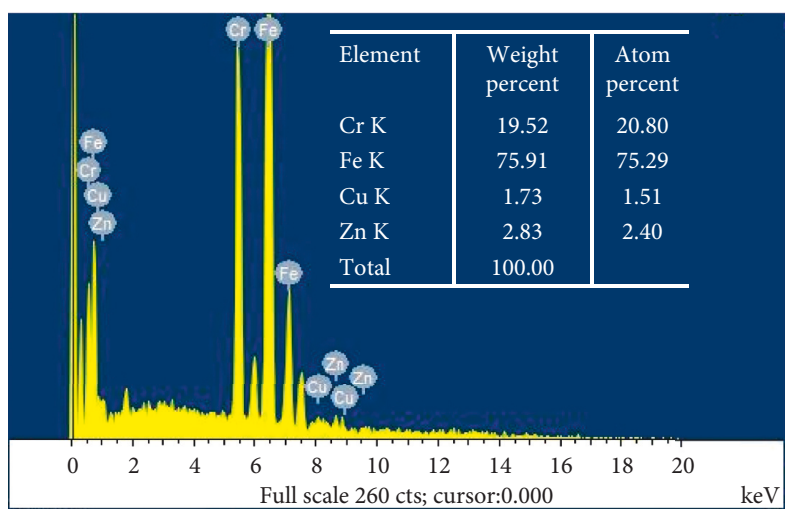

(b)

FIgURE 17: EDS spectral analyses of the hole cross section. (a) SEM. (b) EDS.

verified by comparison with the experimental data. We can state that the approach and the theory used in the present study provide the correct description of the considered phenomena. Conclusions are drawn as follows:

(1) A model for shape transfer in micro-EDM is developed on the basis of the skin effect, the tip effect, and the dielectric breakdown theory. The fundamental cause is the difference in the energy obtained at different positions of the electrode that depends on the pulse-on time, the discharge current density, and the electrode polarity.

(2) The skin effect is determined by fluctuating the frequency of the discharge current rather than having a fixed frequency, and this effect is bound up with the discharge current density.

(3) The discharging current has a dominant effect on the shape of the electrode, and the tip effect may increase as the current increases when its density exceeds a certain value, and this will weaken the skin effect.

(4) Different electrode materials have the same shape change tendency, and the degrees of shape change are different because of the differences of the material properties.

(5) Concave surfaces appear only when the electrode is negatively polarized with respect to the workpiece. A sharp tip is obtained in the contrary condition.

(6) Erosion debris and deposition have no obvious effect on shape changes within the conditions chosen in this paper.

\section{Data Availability}

The data used to support the findings of this study are available from the corresponding author upon request.

\section{Conflicts of Interest}

The authors declare that there are no conflicts of interest regarding the publication of this paper.

\section{Acknowledgments}

The authors would like to thank Liaoning Natural Science Foundation (no. 201602030), National Natural Science Foundation of China (no. 51005027), and China Scholarship Council for financial support.

\section{References}

[1] Y. Y. Tsai and T. Masuzawa, "An index to evaluate the wear resistance of the electrode in micro-EDM," Journal of Materials Processing Technology, vol. 149, no. 1-3, pp. 304-309, 2004.

[2] U. Maradia, R. Knaak, W. Dal Busco, M. Boccadoro, and K. Wegener, "A strategy for low electrode wear in mesomicro-EDM," Precision Engineering, vol. 42, no. 1, pp. 302310, 2015.

[3] Z. Y. Yu, T. Masuzawa, and M. Fujino, "Micro-EDM for three-dimensional cavities - development of uniform wear method -," CIRP Annals, vol. 47, no. 1, pp. 169-172, 1998.

[4] P. Bleys, J.-P. Kruth, B. Lauwers, A. Zryd, R. Delpretti, and C. Tricarico, "Real-time tool wear compensation in milling EDM,” CIRP Annals, vol. 51, no. 1, pp. 157-160, 2002.

[5] C.-S. Lee, E.-Y. Heo, J.-M. Kim, I.-H. Choi, and D.-W. Kim, "Electrode wear estimation model for EDM drilling," Robotics and Computer-Integrated Manufacturing, vol. 36, pp. 70-75, 2015.

[6] K. Suzuki, A. Sharma, M. Iwai, T. Uematsu, K. Shoda, and M. Kunieda, "Electrical discharge machining using electrically conductive CVD diamond as an electrode," New Diamond and Frontier Carbon Technology, vol. 14, no. 4, pp. 35-44, 2004.

[7] W. Chen, X. M. Kang, L. Gu, and W. S. Zhao, "Research on electrically conductive CVD diamond as electrodes in micro and fine EDM," Metal Working, vol. 33, no. 4, pp. 26-28, 2006.

[8] E. Uhlmann and M. Roehner, "Investigations on reduction of tool electrode wear in micro-EDM using novel electrode materials," CIRP Journal of Manufacturing Science and Technology, vol. 1, no. 2, pp. 92-96, 2008.

[9] D. M. Guo, M. Zhang, Z. J. Jin, and B. X. Zuo, "Particle strengthening of the surface of copper electrode for electrical discharge machining," International Journal of Materials and Product Technology, vol. 31, no. 1, pp. 81-87, 2008.

[10] K. P. Rajurkar and Z. Y. Yu, "3D micro-EDM using CAD/ CAM," Cirp Annals, vol. 49, no. 1, pp. 127-130, 2000.

[11] Q. Yin, B. Wang, Y. Zhang, F. Ji, and G. Liu, "Research of lower tool electrode wear in simultaneous EDM and ECM," 
Journal of Materials Processing Technology, vol. 214, no. 8, pp. 1759-1768, 2014.

[12] S. Kumagai, N. Misawa, K. Takeda, and E. T. Abdukarimov, "Plasma-applied machining of a narrow and deep hole in a metal using a dielectric-encased wire electrode," Thin Solid Films, vol. 457, no. 1, pp. 180-185, 2004.

[13] Y. G. Wang, F. L. Zhao, and J. Wang, "Wear-resist electrodes for micro-EDM," Chinese Journal of Aeronautics, vol. 22, no. 3, pp. 339-342, 2009.

[14] D. T. Pham, A. Ivanov, S. Bigot, K. Popov, and S. Dimov, “An investigation of tube and rod electrode wear in micro EDM drilling," International Journal of Advanced Manufacturing Technology, vol. 33, no. 1-2, pp. 103-109, 2007.

[15] M. Mahardika and K. Mitsui, "A new method for monitoring micro-electric discharge machining processes," International Journal of Machine Tools and Manufacture, vol. 48, no. 3-4, pp. 446-458, 2008.

[16] B. Ekmekci, A. Sayar, T. T. Öpöz, and A. Erden, "Geometry and surface damage in micro electrical discharge machining of micro-holes," Journal of Micromechanics and Microengineering, vol. 19, no. 10, article 105030, 2009.

[17] B. Ekmekci and A. Sayar, "Debris and consequences in micro electric discharge machining of micro-holes," International Journal of Machine Tools and Manufacture, vol. 65, no. 1, pp. 58-67, 2013.

[18] B. Schacht, J. P. Kruth, B. Lauwers, and P. Vanherck, "The skin-effect in ferromagnetic electrodes for wire-EDM," International Journal of Advanced Manufacturing Technology, vol. 23, no. 11-12, pp. 794-799, 2004.

[19] Y. Liu, S. M. Meenakshi, F. L. Zhao, and K. P. Rajurkar, "Study on manufacturing freeform surface parts in micro EDM based on skin effect theory," High Technology Letters, vol. 17, no. 4, pp. 439-445, 2011.

[20] S. S. Mujumdar, D. Curreli, S. G. Kapoor, and D. Ruzic, “A model of micro electro-discharge machining plasma discharge in deionized water," Journal of Manufacturing Science and Engineering, vol. 136, no. 3, article 031011, 2014.

[21] Y. V. Serdyuk and S. M. Gubanski, "Computer modeling of interaction of gas discharge plasma with solid dielectric barriers," IEEE Transactions on Dielectrics and Electrical Insulation, vol. 12, no. 4, pp. 725-735, 2005.

[22] A. Descoeudres, C. Hollenstein, G. Wälder, R. Demellayer, and R. Perez, "Time- and spatially-resolved characterization of electrical discharge machining plasma," Plasma Sources Science and Technology, vol. 17, no. 2, article 024008, 2008.

[23] R. Vogelsang, B. Fruth, T. Farr, and K. Fröhlich, "Detection of electrical tree propagation by partial discharge measurements," European Transactions on Electrical Power, vol. 15, no. 3, pp. 271-284, 2005.

[24] D. V. Skobel'tsyn, Physical Processes in Lasers, Springer, Boston, MA, USA, 1973.

[25] P. Perez, H. Rojas, G. Walder, and R. Flukiger, "Theoretical modeling of energy balance in electroerosion," Journal of Materials Processing Technology, vol. 149, no. 1-3, pp. 198-203, 2004.

[26] S. Cetin, A. Okada, and Y. Uno, "Effect of debris distribution on wall concavity in deep-hole EDM," JSME International Journal Series C, vol. 47, no. 2, pp. 553-559, 2004.

[27] K. Furutani, H. Sato, and M. Suzuki, "Influence of electrical conditions on performance of electrical discharge machining with powder suspended in working oil for titanium carbide deposition process," International Journal of Advanced Manufacturing Technology, vol. 40, no. 11-12, pp. 1093-1101, 2009. 


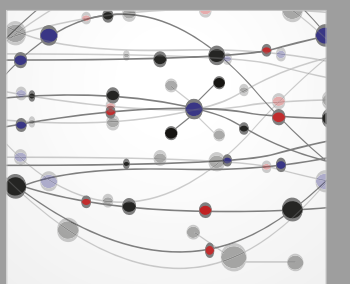

The Scientific World Journal
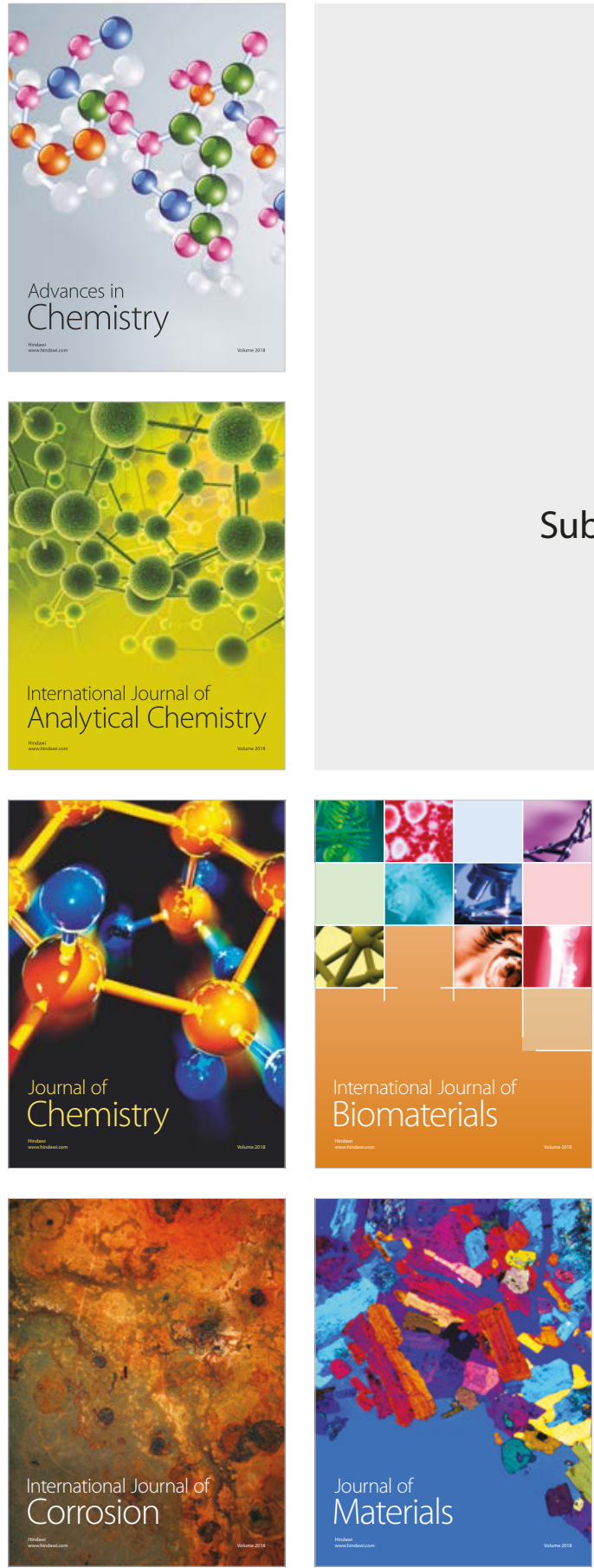

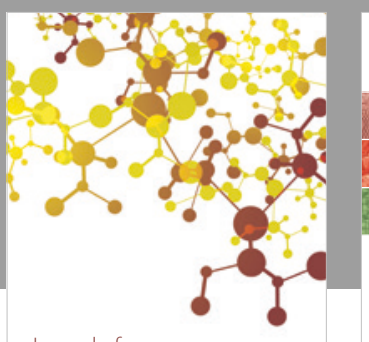

Journal of

Applied Chemistry
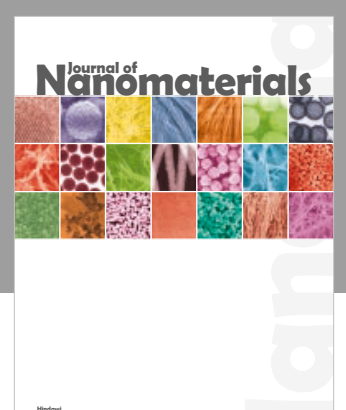

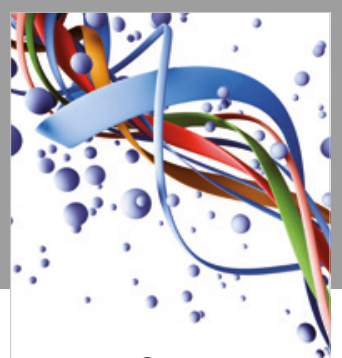

Scientifica

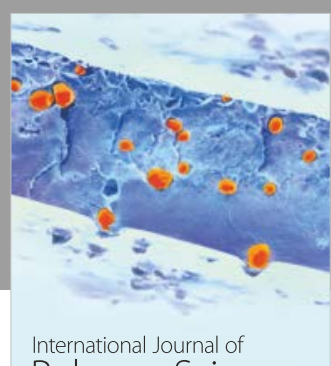

Polymer Science

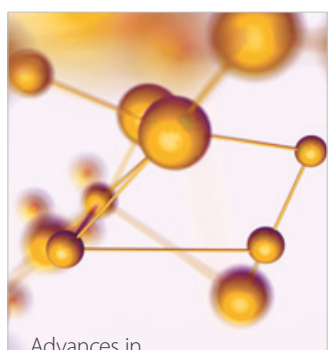

Physical Chemistry
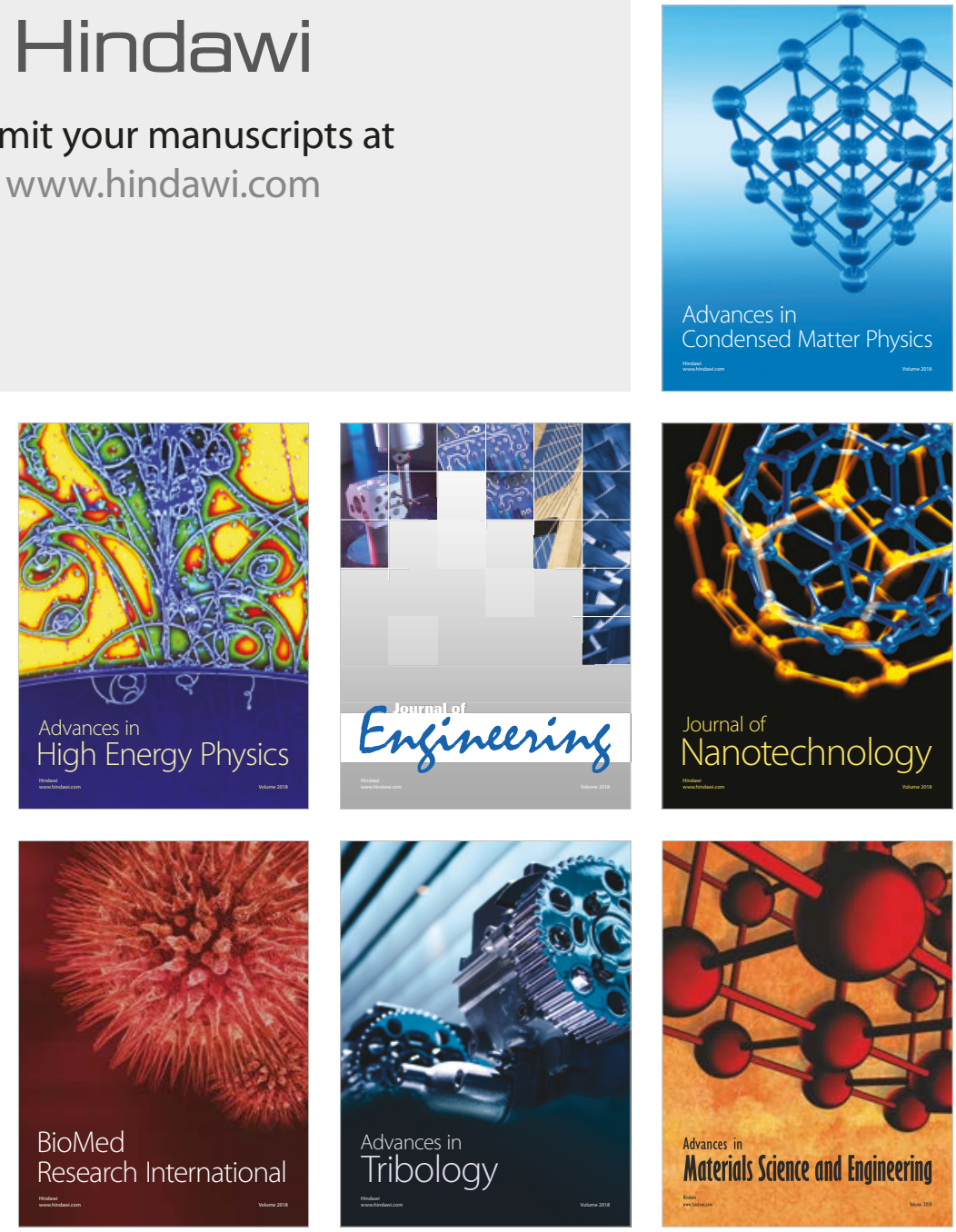